\title{
Leg salvage in an elderly patient with a circumferential avulsion
}

\author{
Duncan Nickerson MD, Christopher Taylor MD, Nicholas Carr MD FRCSC \\ Division of Plastic Surgery, University of British Columbia and Vancouver General Hospital, \\ Vancouver, British Columbia
}

\begin{abstract}
D Nickerson, C Taylor, N Carr. Leg salvage in an elderly patient with a circumferential avulsion. Can J Plast Surg 1999;7(4):191-193.

The present paper reports the case of an elderly woman who sustained an extensive lower extremity skin avulsion injury. Limb salvage was achieved by using split-thickness skin grafts that were harvested from the avulsed skin. The case is noteworthy because of the advanced age of the patient, the extent of the injury, the method of back-table skin graft harvest and the successful outcome.
\end{abstract}

Key Words: Elderly; Skin avulsion; Skin grafts

\section{Sauvetage de la jambe chez une patiente âgée présentant une avulsion circonférentielle}

RÉSUMÉ : Le présent article rapporte le cas d'une patiente âgée qui a subi une blessure importante du membre inférieur avec avulsion de la peau. On a réussi à préserver le membre en utilisant des greffons de peau divisés dans l'épaisseur et prélevés sur la peau arrachée. Ce cas mérite d'être signalé à cause de l'âge avancé de la patiente, de l'étendue de la blessure, de la méthode de prélèvement des greffons cutanés sur une table stérile dans la salle d'opération et de la réussite de l'intervention.

$\mathrm{T}$ he present report describes an 81-year-old woman who was driven over by a large, three-axle delivery truck travelling at approximately $50 \mathrm{~km} / \mathrm{h}$.

Examination in the emergency room demonstrated an alert, tachypneic and tachycardic woman. Her injuries included multiple right-sided rib fractures and a probable pulmonary contusion, a fracture of the right first metatarsal, and circumferential avulsion of the skin and subcutaneous fat of her left lower extremity from the level of the groin crease to the level of the malleoli. The left buttock and proximal onethird of the posterior thigh were spared. The avascular, avulsed portion remained attached posteriorly by a narrow skin bridge (Figure 1). The patient's left foot was sensate and vascular.

This vibrant woman emphasized that she lived independently, was quite active and walked extensively. She and her family expressed a strong preference to attempt lower limb salvage.

Correspondence: Dr D Nickerson, c/o Research Section, Division of Plastic Surgery, Plastic Surgery and Burn Unit, 2nd Floor, Laurel Pavilion, 855 West 12th Avenue, Vancouver, British Columbia V5Z 1 M9. Telephone 604-875-4084, fax 604-875-5614,e-mail duncann@unix.ubc.ca

\section{PATIENTS AND METHODS}

The patient was taken to the operating room on an urgent basis for debridement. In the operating room, the avascular skin was removed en bloc, the leg was debrided and the wound was irrigated with $6 \mathrm{~L}$ of warm saline. Intraoperatively, the patient demonstrated impaired coagulation, became hypotensive and showed electrocardiogram signs of myocardial ischemia, though not of outright infarction. Consequently, completion of debridement was expedited, and she was transferred to the intensive care unit with saline compresses on the left leg. Perioperatively, she received $9 \mathrm{U}$ of packed red blood cells, $3 \mathrm{~L}$ of crystalloid, $4 \mathrm{U}$ of fresh frozen plasma, $5 \mathrm{U}$ of platelets, and $10 \mathrm{U}$ of cryoprecipitate.

On the sterile back table in the operating room, the avulsed skin and subcutaneous tissue was stretched over a large, inverted sterile instrument pan and held taut with a combination of manual traction and towel clips (Figure 2). An air dermatome was then used to harvest split-thickness skin grafts (STSG) at a thickness of 0.010 . The skin was meshed at a 1.5:1 ratio, spread on petrolatum gauze and refrigerated in sterile containers at $4^{\circ} \mathrm{C}$. In this fashion, STSG accounting for approximately $14 \%$ body surface area, with minimal waste at the edges, were harvested. Stabilization of 


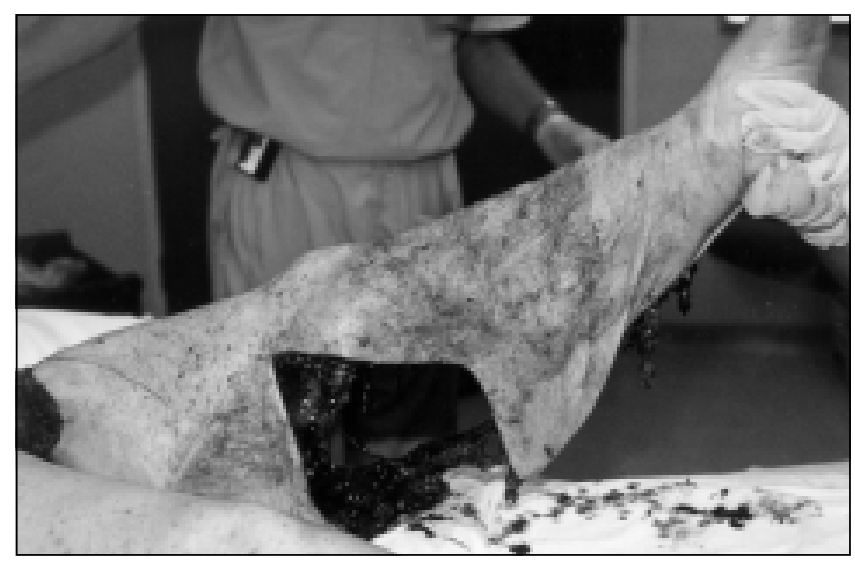

Figure 1) The degloved left lower extremity, showing the hanging avulsed skin flap

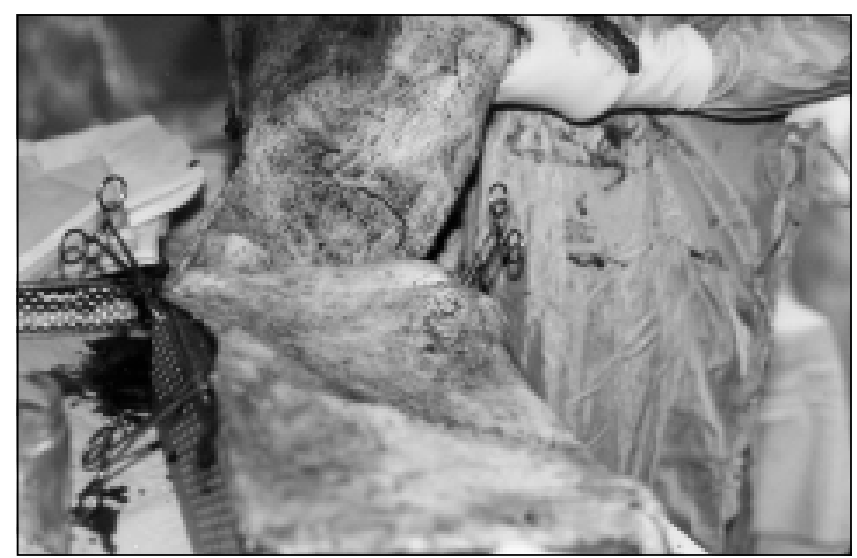

Figure 2) The avulsed skin flap, spread on an instrument pan in preparation for harvest of split-thickness skin graft

the patient's condition allowed return to the operating room on the second postinjury day. A pedicled lateral gastrocnemius muscle flap was performed to cover exposed peroneal nerve. The previously harvested STSG were initially applied distally and covered approximately $80 \%$ of the wound. The proximal anterior thigh was covered with a cadaveric allograft.

Foul odor from the occlusive dressing prompted removal at postoperative day 3 . The autografts were all well adherent, but a portion of the allograft was separating in the midst of thick, purulent discharge. The autografts were rewrapped in bacitracin-soaked gauze, while the nonadherent portion of allograft was debrided at the bedside and the resultant open area was dressed with silver sulfadiazine cream. Cultures revealed enterococcus and Acetinobacter baumannii, which were treated with vancomycin, ceftazidime and ciprofloxacin. On postinjury day 10 , initially allografted areas now open were resurfaced with autograft STSG harvested from the right anterior thigh. Adherent allograft on the proximal thigh was left in place because prolonging the operative time to replace it at that time would unnecessarily increase operative risk. Of note, there was a $100 \%$ take of the autograft initially harvested from the avulsed skin.

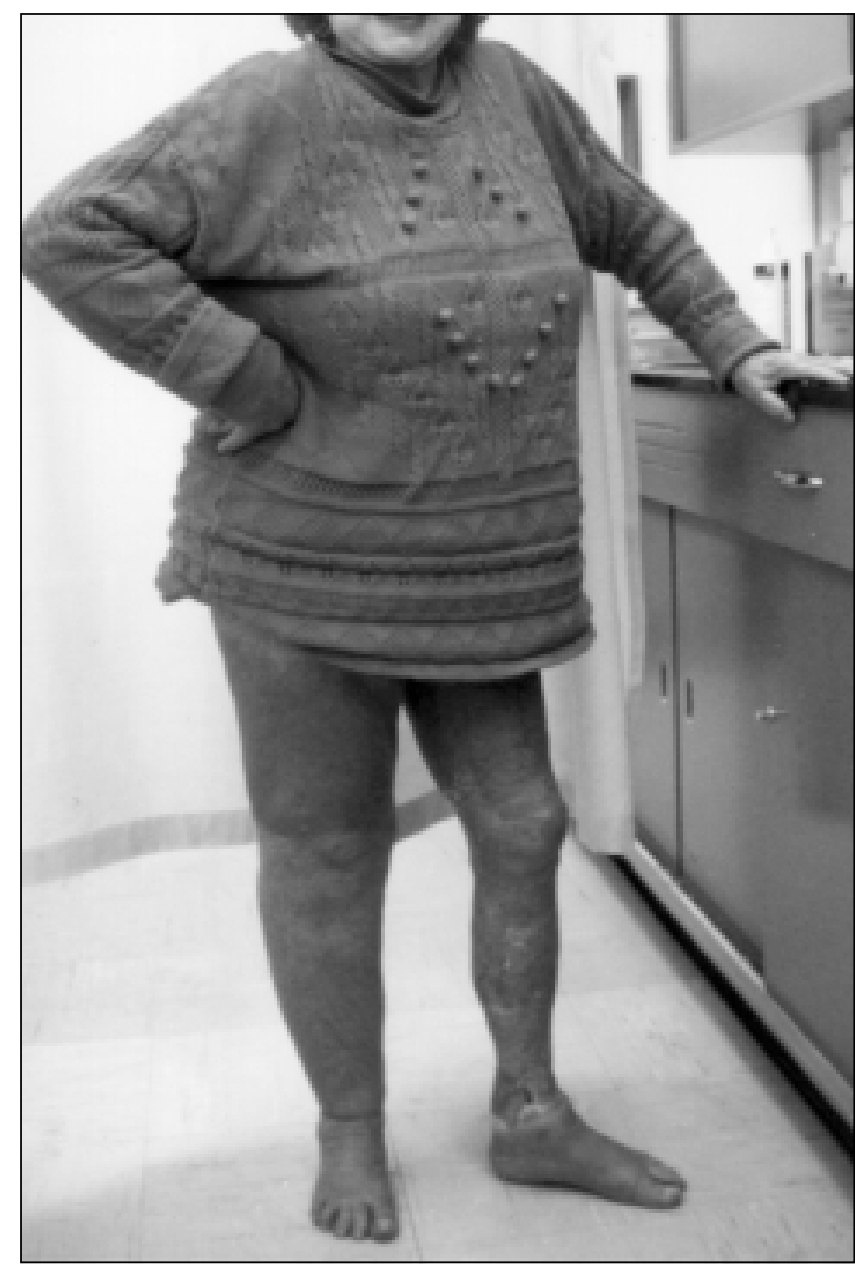

Figure 3) The patient at six months postinjury, demonstrating weightbearing with the left lower extremity and a reasonable cosmetic result

Due to her rib fractures and pulmonary contusions, the patient was not extubated until the postinjury day 20. One further operation replaced the allograft on the proximal thigh with autograft.

At three months postinjury, the patient resumed independent living in her own home with full weight-bearing ability (Figure 3 ). She has a $10^{\circ}$ popliteal flexion contracture.

\section{DISCUSSION}

Farmer (1) described reapplying avulsed skin as a fullthickness graft in 1939. Since that time, several authors have reported using both full- and split-thickness grafts $(2,3,4)$. Replacing the avulsed flap as a full-thickness skin graft may be ideal from a cosmetic point of view, but poor viability of the deep dermis on the underside of the graft impairs take if not adequately debrided. With specific reference to this case, immediate reapplication of the avulsed skin would have been impractical as the patient's hemodynamic instability necessitated a short first operation. Harvesting split-thickness grafts from the avulsed part and refrigerating them for later application minimized the operative time. 
In a series of 42 patients with circumferential lower extremity avulsion injuries treated with full-thickness skin graft replacement of the avulsed flap with an average patient age of 34 years, average take of the grafts was $91 \%$, and five patients were left with a 'mild' popliteal flexion contracture (2). This case report demonstrates limb salvage in an 81-year-old woman who has enjoyed a full return to independent living after $100 \%$ take of STSG from a near total circumferential lower extremity skin avulsion. She does have a mild popliteal flexion contracture and a contour abnormality due to the lateral gastrocnemius flap, and the loss of subcutaneous fat. However, the patient is pleased with the overall result of having kept a functional lower extremity.

Use of the avulsed flap in this manner avoided increased donor-site morbidity if the skin grafts had been obtained from noninjured donor sites, or, alternatively, the morbidity of an amputation. The high energy expenditure associated with a very proximal above-knee amputation makes it unlikely that this particular patient would have successfully returned to ambulation without this extremity.

\section{CONCLUSIONS}

In conclusion, the concept of using split-thickness grafts from an avulsed flap to cover a degloved limb is applicable even in elderly patients with massive skin loss.

ACKNOWLEDGEMENTS: The authors thank Dr C Verchere and Ms Wendy Cannon, Division of Plastic Surgery Research Assistant, for their assistance in preparing this manuscript.

\section{REFERENCES}

1. Farmer AW. Treatment of avulsed skin flaps. Ann Surg 1939;110:951.

2. Jeng SF, Wei FC. Technical refinement in the management of circumferentially avulsed skin of the leg. Plast Reconstr Surg 1997;100:1434-41.

3. Hidalgo DA. Lower extremity avulsion injuries. Clin Plast Surg 1986;13:701-10

4. Kalisman M, Wexler MR, Yeschua R, Neuman Z. Treatment of extensive avulsions of skin and subcutaneous tissues. J Dermatol Surg Oncol 1978;4:322-7.

5. Waters RL, Perry J, Antonelli D, Hislop H. Energy cost of walking of amputees: the influence of level of amputation. J Bone Joint Surg [Am] 1976;58:42-6. 